\title{
Diagnostic Accuracy and Appropriate Cut Off Value of Risk of Malignancy Index in Preoperative Discrimination Between Malignant and Benign Ovarian Tumors: Prospective Cross-sectional Study
}

bezza Kedida Dabi ( $\sim$ bezzakedida2@gmail.com )

Jimma Institute of Health Sciences: Jimma University https://orcid.org/0000-0002-1507-4681

Fanta Asefa Disasa

Jimma University College of Public Health and Medical Sciences

Ayantu Kebede Olika

Jimma University College of Public Health and Medical Sciences

\section{Research Article}

Keywords: Risk of malignancy index, CA 125, ovarian mass, diagnostic accuracy, cut off, Ethiopia

Posted Date: July 19th, 2021

DOl: https://doi.org/10.21203/rs.3.rs-707734/v1

License: (c) (1) This work is licensed under a Creative Commons Attribution 4.0 International License.

Read Full License 


\section{Abstract}

\section{Background}

Risk of malignancy index (RMI) is scoring system which was introduced to differentiate between benign and malignant ovarian tumor. It incorporates CA-125, ultrasound score and menopausal status for prediction of ovarian malignancies in preoperative period. There is no universal screening method to discriminate between benign and malignant adnexal masses yet. So, this study was conducted to determine the diagnostic accuracy of RMI and determine best cut off value for RMI.

\section{Methods}

Prospective cross-sectional study was carried out among women with ovarian mass admitted to Gynecology ward and operated from September 1, 2019 to June 30, 2020.Data analysis was carried out using SPSS version 26. CA-125 level, menopausal status and ultrasound score were used to calculate RMI. Finally, RMI score was compared to histopathology result used as gold standard.

\section{Results}

Ninity nine patients were enrolled in this study. Prevalence of benign ovarian tumors were $61.6 \%(61 / 99)$ and that of malignant ovarian tumors were $38.4 \%$ (38/99). The mean age for benign tumors was $30 \pm 9 \mathrm{yrs}$ and the mean age for malignant tumors was $50.6 \pm 10.8 \mathrm{yrs}$. Among benign tumors, serous cystadenoma was the most common (36\%), followed by dermoid cyst (32.9\%), mucinous cyst adenoma (14.8\%). The most common malignant ovarian tumor was serous cyst adenocarcinoma (63.2\%), followed by mucinous cystadenocarcinoma (23.8\%) and dysgerminoma (5.3\%). Overall, using RMI score cut off value 220 has good sensitivity (84.2\%), specificity (77\%), PPV (69.5\%), NPV (88.7\%) and diagnostic accuracy $(79.8 \%)$ for discriminating between benign and malignant ovarian tumors.

\section{Conclusion}

From this study there were high proportion of women with RMl>=220 in malignant ovarian tumors group. The study shows that there is significant role of RMI in prediction of ovarian malignancy thus helping in deciding which patients need referral to a center where gynecologic oncologists are available. It is good practice to use it in developing countries including our country because of its simplicity, safety and applicability in initial evaluations of patients with adnexal mass.

\section{Introduction}

Ovarian cancer is the second most common type of female reproductive cancer, and more women die from ovarian cancer than cervical cancer and uterine cancer combined(1). Woman's risk at birth of ovarian cancer at some time in her life is $1 \%$ to $1.5 \%$ and that of dying from cancer is almost $0.5 \%(1)$.In $20184.4 \%$ of all cancer related mortality is attributed to ovarian cancer(2). It is the seventh most common cancer in women, and incidence rates are highest in developed countries $(2,3)$. The incidence of 
ovarian cancer increases with age. Interest in early detection as a method of reducing mortality developed with the discovery of serum tumor markers associated with ovarian malignancies particularly CA 125 and with the improved diagnostic accuracy of pelvic ultrasonography(3).

The high mortality rate in ovarian malignancy is mainly due to late detection of disease(4). If it can be detected at an early stage then disease can be treated with optimal primary cytoreduction and achievement of optimal cytoreduction (single most important prognostic criteria) becomes possible(5).Pelvic examination is not specific and sensitive in detecting ovarian malignancy. Cancers detected by pelvic examination are often far advanced, so pelvic examination for screening is not recommended(5). Tumor markers when used alone are not specific to be used as screening test. They are raised in a number of benign conditions and are not raised in poorly differentiated cancer, borderline tumors and mucinous tumors(6). In a prospective study conducted to evaluate sensitivity and specificity of CA-125 as a marker for ovarian malignancy concluded that measurement of serum CA-125 levels, particularly at a reference value of $35 \mathrm{IU} / \mathrm{mL}$, is not sufficiently sensitive to be used alone as a screening test for the detection of ovarian cancer(6). Ultrasound can differentiate between solid, cystic and multilocular masses, although malignancy cannot be diagnosed, unequivocally(6).Risk of malignancy index is a scoring system which can be introduced to differentiate between malignant and benign ovarian tumor(5). RMI in ovarian malignancy incorporates CA-125, USG and Menopausal status for Predicting if an ovarian mass is malignant or benign, screening for suspected pelvic mass, deciding appropriate management protocol and triage of patients(5). This score has given significantly superior results than the use of a single parameter(7). RMI Score (RMI) -Total Score = USG Score X Menopausal Score X CA -125(U/ml). USG score: 1 - No risk factor or one risk factor, 3 - Two - Five risk factors. High risk factors in USG: Multiloculated cysts, solid areas, bilateral lesions, ascites and evidence of metastasis. Menopausal status: 1- Pre- menopausal, 3 - Post-menopausal

CA125- Absolute value (IU/ml). The anatomic site of ovaries makes it inaccessible to simple diagnostic procedure like smear and biopsy like cancers of uterus and cervix(4). Absence of effective screening method for ovarian cancer yet is another contemporary challenge. Patients with malignant tumors should be evaluated by gynecologic oncologist as the quality of cytoreduction surgery and surgical staging/ lymph node dissection are critical prognostic parameters in ovarian malignancy $(5,7)$. The finding of an ovarian mass raises questions about the most suitable management and the place where this management is to be implemented(7). The finding of the study will rebound to benefit the society considering that ovarian tumor is one of the major health problems of women in all age groups, as there is no effective screening strategy yet in the world. It will also put the basis for health policy makers and resource allocators to reconsider strengthen further study to decrease mortality associated with ovarian tumor. The finding of the study will also help us to triage patients preoperatively whether to be operated by Gynecologic oncologist or General Gynecologist thus decreasing health costs.

Local data on cancer epidemiology in Ethiopia are lacking(8). Studies from the Global Burden of Disease Cancer Collaboration and the Cancer Incidence in Five Continents Collaboration have estimated cancer incidence by cause for countries globally, and both studies used evidence from neighboring African 
countries to estimate cancer incidence in Ethiopia(8). In Ethiopia in females 15 years and older, the most common cancer was breast cancer, followed by cervical cancer , ovarian cancer, colorectal cancer, and leukemia(8). Ovarian cancer is $3^{\text {rd }}$ most common cancer next to breast and cervical cancer among female older than 15yrs old with crude incidence rate(CIR) of 4.9 per 100,000 population and age standardized incidence rate(ASIR) of 8.1 per100,000 population(8). Based on 2013 data from the Addis Ababa Cancer Registry, breast cancer accounted for $31.4 \%$, cervical cancer for $14.3 \%$ and ovarian cancer for $6.3 \%$ of all cancer cases(9)

As the symptoms of the ovarian cancer are very vague like bloating, pelvic or abdominal pain, poor appetite, feeling full quickly, and urinary urgency it is also known as "silent killer". Thus, silent occurrence and slow progression, added to the fact that few effective methods for early diagnosis and no universal screening method for diagnosis of malignant ovarian tumor exists, made its mortality rate highest among gynecologic malignancies(10-12). Of all gynecologic malignancies ovarian cancer has the worst prognosis since is detected at advanced stage(13). The main challenge is to identify patients with highrisk adnexal masses preoperatively and this is compounded by the lack of definitive noninvasive diagnostic test(14). The discrimination between benign and malignant adnexal mass is central to decision regarding clinical management and surgical planning in such patients(15).Jacob et.al originally developed a risk of malignancy index based on ultrasound findings, menopausal status and CA125(15).The main advantage of this method compared to other approaches such as color Doppler ultrasound(15) or use of different tumor markers $(16,17)$ is that RMI can be used easily in less specialized unit (18).

United states preventive service task force found adequate evidence that screening for ovarian cancer doesn't reduce ovarian cancer mortality and thus recommend against screening for ovarian cancer in asymptomatic women who are not known to have high risk hereditary cancer syndrome $(19,20)$. Prompt identification of ovarian malignancies and referral to Gynecologic oncologist can enhance patient survival, but a single method which can accurately predict ovarian malignancies are unavailable(21).RMI is widely studied for prediction of ovarian malignancies in western populations. However, little is known about its implication in developing countries(21-23). Subsequent studies have shown RMI is reliable tool in differentiating benign and malignant adnexal mass $(24,25)$. Because of this Authors wish to see if RMI score, can be applied in present low resource setting of our population for setting up a better diagnosis, referral and management system

\section{Methods}

\section{Study area and design}

An institutional based Prospective cross-sectional study was employed in Jimma University medical center, Jimma zone, from September 1, 2019 to June 30, 2020. Jimma University teaching Hospital (JUTH) is one of the oldest public hospitals in the country. It was established in 1922 G.C. Geographically, it is located in Jimma city $352 \mathrm{~km}$ to southwest of the capital Addis Ababa, Ethiopia. It has been 
governed under the Ethiopian government by the name of "Ras Desta Damtew Hospital" and later "Jimma Hospital" during Dergue regime and currently Jimma University Specialized Teaching Hospital and recently Jimma Medical center. Currently it is the only teaching and referral hospital in the south western part of the country providing service for approximately 115,000 in patient, 16000 outpaient, 11000 emergency case and 4500 deliveries per year.it gives services to about 15 million populations coming from Oromia, Gambella and SNNP(26) .

\section{Study participants}

All patients with adnexal mass who visited Gynecologic OPD of Jimma Medical Center and admitted to gynecology ward and operated during study period were included in the study. Patients with previous history of ovarian cancer, abdominal mass other than ovarian mass was excluded. For patients who had undergone hysterectomy age cut off point greater than or equals to 51 .3yrs was considered as postmenopausal.

\section{Sample size and sampling technique}

Purposive sampling technique was employed. All patients with adnexal mass who were admitted to gynecology ward of Jimma medical center and underwent laparotomy were included in the study. A total of 99 patients with adnexal mass were registered for surgery and provided informed consent to participate in the study.

\section{Data collection methods and tools}

Structured questionnaire which was prepared in English by reviewing related relevant literature $(5,7,10,15,17,21,25)$ and translated to regional language Afaan Oromoo by language experts was used to collect data. Data was collected by interviewing the patients and reviewing their charts. The questionnaire has seven parts. The $1^{\text {st }}$ part assesses sociodemographic characteristics; the $2^{\text {nd }}$ part assesses menstrual status; the $3^{\text {rd }}$ part evaluate patients signs and symptoms; the $4^{\text {th }}$ part has absolute value of CA-125; the $5^{\text {th }}$ part assess ultrasound findings of adnexal mass; the $6^{\text {th }}$ part has RMI score absolute value and the last part has histopathology result of the adnexal mass. USG done by radiologist or Gynecologist were used for USG score. Two year-II Gynecology residents were selected to collect data after getting proper training by principal investigator. At the end of each data collection day the questionnaire was checked for consistency and completeness and close supervision was carried out during data collection by principal investigator

\section{Data analysis}

The collected data were entered into epidata version 4.6.0.2 and then exported to SPSS (statistical packages for social sciences) version 26 computer software for analysis. Descriptive statistics and analytic statistics methods were used for analysis. To determine the best cut off value of RMI, Receiver 
operating characteristic curve (ROC) was plotted and odds ratio with $95 \% \mathrm{Cl}$ was calculated. Best cut off value was chosen according to highest sensitivity and lowest false positive rate. Histopathology result was used as gold standard to differentiate malignant from benign adnexal mass. P-value less than 0.05 considered statistically significant. Finally obtained results were presented using tables and figures.

\section{Results}

A total of 99 patients were enrolled in this study. The incidence of benign ovarian tumor in all patients presented with adnexal mass and operated for suspected ovarian malignancy at JMC is $61.6 \%$ and that of malignant ovarian tumor is $38.4 \%$. From this study the youngest patient was 15 years old and the oldest patient is 73 years old. All benign tumors were in age group 15-54. Malignant tumors were found in age group 25-65 and older than sixty-five years. Total of 63 patients were premenopausal and 36 were postmenopausal. Eighty point six of ovarian mass in postmenopausal patients were malignant and $14.3 \%$ in premenopausal where malignant $[(p=.000$, cramers $V=0.66$ (large effect size $)]$. Among premenopausal patients $28.6 \%$ were in age group $15-24$, and $72.4 \%$ were in age group $25-54$. Among post-menopausal patients $21(58.3 \%)$ were in age group 25-54;12(33.3\%) patients were in age group 55-64 and $3(8.3 \%)$ were $>=65$ years. The mean age of women with benign tumors were $30 \pm 9 y$ years and the mean age for malignant tumor were $50.6 \pm 10.8$ years. The difference in age between the two groups was statistically significant $95 \% \mathrm{Cl}[16.4-24.5, \mathrm{P}=.000, \mathrm{t}=9.99]$. Majority of patients were from rural $62(62.6 \%)$ and the rest were from urban $37(37.4 \%)$. Fifty $(50.5 \%)$ patients were Muslims in religion $30(30.3 \%)$ were Orthodox, $17(17.2 \%)$ were protestants and $2(2 \%)$ were Catholic. Majority of patients were Oromo in ethnicity (58.6\%), followed by Amhara (12.1\%), Kaffa (12.1\%), Waliyita (4\%) and others (1\%). Seventy-six $(76.8 \%)$ patients were married, $12(12.1 \%)$ were single,4(4\%) were divorced and $7(7 \%)$ were widowed. Majority of patients can't read and write (58.6\%), $11.1 \%$ learned up to grade 8 and $12.1 \%$ were in grade 9 10 . The mean income of patients was $2809 \pm 1928$ birr. There was moderate association between income level and histopathology result(eta=0.541)

Table 1: Distribution of cases according to age, menstrual status, USG score, serum CA-125 level, RMI 


\begin{tabular}{llll} 
Parameters & Benign $(\mathrm{n}=61)$ & Malignant $(\mathrm{n}=38)$ & P-value \\
\hline Mean age (in years) & $30 \pm 9$ & $50.6 \pm 10.8$ & .000 \\
\hline
\end{tabular}

\section{USG characteristics}

\begin{tabular}{llll}
\hline Multilocular cyst & $11(34.4 \%)$ & $21(65.6 \%)$ & .000 \\
Thick septation(>=2mm) & $31(49.2 \%)$ & $32(50.8 \%)$ & .062 \\
bilaterality & $1(33.3 \%)$ & $2(66.7 \%)$ & .308 \\
solid component & $37(44.0 \%)$ & $47(56.0 \%)$ & .006 \\
ascites & $2(6.3 \%)$ & $30(93.7 \%)$ & .000 \\
\hline Serum CA-125(U/ml) \pm Sd & $71.9 \pm 90.5$ & $798 \pm 918$ & .000 \\
\hline RMI (mean \pm Sd) & $164.9 \pm 277.8$ & $4386.4 \pm 5153.6$ & .000 \\
\hline USG score 3 & $20(31.3 \%)$ & $44(68.7 \%)$ & .000 \\
\hline USG score 1 & $31(88.6 \%)$ & $4(11.4 \%)$ & \\
\hline RMI<220 & $47(88.7 \%)$ & $6(11.3 \%)$ & .000 \\
RMI>=220 & $14(30.4 \%)$ & $32(69.6 \%)$ & \\
\hline Menstrual status & & & .000 \\
\hline Premenopausal & $54(85.7 \%)$ & $9(14.3 \%)$ & .000
\end{tabular}

$\mathrm{Sd}=$ Standard deviation

In this study multilocular cysts were found in $32.3 \%$ (32/99) of cases. Out of which $34.4 \%(11 / 32)$ cases were benign and $65.6 \%(21 / 32)$ were malignant by histopathology. Multilocular cyst is higher in malignant group compared to benign and it was also statistically significant $(\mathrm{P}=000)$. thick septation was found in $63.6 \%$ (63/99) of cases and out of which $49.2 \%$ (31/63) were benign and 50.8\% (32/63) were malignant but the P-value .062 is not statistically significant in our study. Bilaterality in adnexal mass was found $3 \%(3 / 99)$ of cases and out of which $33.3 \%(1 / 3)$ were benign and $66.7 \%(2 / 3)$ were malignant but it fails to be statistically significant in our study $(P=.308)$. Solid component was found in $44 \%(37 / 84)$ of benign cases and $56 \%$ (47/84) cases of malignant cases. More solid component was found in malignant ovarian tumor than benign ovarian tumor and it was found to be statistically significant with P-value of .006.Ascites was found in only $6.3 \%(2 / 32)$ of benign cases and $93.8 \%(30 / 32)$ of malignant cases. The study showed larger cases of malignant adnexal mass has ascites compared to benign adnexal mass which was statistically significant with $p$-value of .000 .we assigned ultrasound score of 3 based on presence of two or more finding or score of 1 based on absence specific finding or presence of one finding to study subjects based on USG findings. Thirty-five-point four percent $(35 / 99)$ 
had score of 1 and $64.6 \%$ (64/99) had score of 3. with USG score of 1 benign tumor was found in $88.6 \%$ $(31 / 35)$ and malignant tumor was found in $11.4 \%$ (4/35). With USG score of 3 malignant tumor was found in $68.7 \%$ (44/64) cases and benign tumor was found in 31.3\% (20/64) cases. USG score of 3 with malignant tumor was higher than USG of 3 with benign tumor $(P=.000)$. The mean value of RMI for malignant adnexal mass was $(4386.4 \pm 5153.6)$ compared to the mean value of $(164 \pm 277.8)$ for benign adnexal mass $(P=.000)$. The mean value of $C A-125$ for malignant adnexal mass was $(798 \pm 918) \mathrm{U} / \mathrm{ml}$ compared to the mean value of benign adnexal mass $(71.9 \pm 90.5) \mathrm{U} / \mathrm{ml}(P$ value $=.000)$.

Table 2: Diagnostic efficacy of RMI score as a marker of malignancy in JMC,2020

\begin{tabular}{lllll} 
& & \multicolumn{2}{c}{ histopathology } & Total \\
\cline { 2 - 4 } & & benign & malignant & \\
\hline \multirow{2}{*}{ RMI score } & $<220$ & 47 & 6 & 53 \\
\cline { 2 - 5 } & $>=220$ & 14 & 32 & 46 \\
\hline \multirow{2}{*}{ Total } & 61 & 38 & 99 \\
\hline
\end{tabular}

Sensitivity specificity PPV NPV diagnostic accuracy

\section{$84.2 \% \quad 77 \% \quad 69.5 \% \quad 88.7 \% \quad 79.8 \%$}

As shown on table 2 above, RMI score >=220 has good sensitivity of $84.2 \%$; specificity of $77 \%$; positive predictive value of $69.5 \%$; negative predictive value of $88.7 \%$ and diagnostic accuracy of $79.8 \%$. The binary logistic regression analysis shows that RMI score $>=220$ has 17.9 times more likely to have malignant ovarian tumor $95 \% \mathrm{Cl}[5.7-47.6], \mathrm{P}<0.05$. For every 1 -unit increment in RMI value there is $0.3 \%$ increment in the risk of ovarian ca.

The ROC curve for cut of point of 220 for RMI has excellent area under the curve [AUC:90.9\%, $(95 \% \mathrm{Cl}$ .843-.976] as depicted by figure 2 . As shown by table $2,69.5 \%(32 / 46)$ of patients with malignant adnexal mass shows positive test result with RMI. $88.7 \%(46 / 52)$ patients with benign adnexal mass showed negative test result with RMI

As shown by figure $3 \mathrm{RMI}$ has larger area under the curve when compared to CA-125.This means RMI has better sensitivity and specificity when compared to CA-125 alone to discriminate between benign and malignant adnexal mass. At cut off point of $96 \mathrm{IU} / \mathrm{ml}$ CA-125 has sensitivity, specificity, PPV, NPV and diagnostic accuracy of $84.2 \%, 70.5 \%, 64 \%, 87.8 \%, 75.8 \%$ respectively.

Table 3: Evaluations of RMI, USG score, CA-125, menopausal status in JMC,2020 


\begin{tabular}{|llllll|}
\hline & $\begin{array}{l}\text { Sensitivity } \\
(\%)\end{array}$ & $\begin{array}{l}\text { Specificity } \\
(\%)\end{array}$ & $\begin{array}{l}\text { PPV } \\
(\%)\end{array}$ & $\begin{array}{l}\text { NPV } \\
(\%)\end{array}$ & $\begin{array}{l}\text { Diagnostic accuracy } \\
(\%)\end{array}$ \\
\hline RMI>=220 & 84.2 & 77 & 69.5 & 88.7 & 79.8 \\
\hline USG score 3 & 83.5 & 50.8 & 53.1 & 88.6 & 65.7 \\
\hline CA-125>=96 & 84.2 & 70.5 & 64 & 87.8 & 75.8 \\
\hline $\begin{array}{l}\text { Menopausal } \\
\text { score3 }\end{array}$ & 73.7 & 75.5 & 64.6 & 84.4 & 77.2 \\
\hline
\end{tabular}

As shown by table 3 above when we comparing diagnostic efficacy of individual parameters for CA$125>=96$, USG score of 3 , menopausal score of 3 to RMI>=220 it has better sensitivity, specificity, PPV, NPV and diagnostic accuracy.

Table 4:Comparison of sensitivity, specificity, PPV, NPV and diagnostic accuracy of RMI at different cut off points in JMC,2020

\begin{tabular}{|c|c|c|c|c|c|c|c|c|}
\hline $\begin{array}{l}\text { Cut off } \\
\text { point RMI }\end{array}$ & $\begin{array}{l}\text { Sensitivity } \\
(\%)\end{array}$ & $\begin{array}{l}\text { Specificity } \\
(\%)\end{array}$ & $\begin{array}{l}\text { PPV } \\
(\%)\end{array}$ & $\begin{array}{l}\text { NPV } \\
(\%)\end{array}$ & $\begin{array}{l}\text { Diagnostic } \\
\text { accuracy (\%) }\end{array}$ & $+\mathrm{LR}$ & -LR & $\begin{array}{l}\text { Odds } \\
\text { ratio } \\
\mathrm{Cl} \\
95 \%\end{array}$ \\
\hline 175 & 84 & 75.4 & 68 & 87.5 & 78 & 3.41 & 0.21 & $\begin{array}{l}16.4 \\
5.73- \\
46.68\end{array}$ \\
\hline 200 & 84.2 & 75.4 & 68.8 & 88.5 & 78.8 & 3.42 & 0.21 & $\begin{array}{l}16.4 \\
5.73- \\
46.68\end{array}$ \\
\hline 220 & 84.2 & 77 & 69.5 & 88.7 & 79.8 & 3.66 & 0.21 & $\begin{array}{l}17.9 \\
6.22- \\
51.50\end{array}$ \\
\hline
\end{tabular}

As depicted by table 4 above, at cut off point 175 RMI has sensitivity $84 \%$, specificity $75.4 \%$, PPV $68 \%$, NPV $88.5 \%$ and diagnostic accuracy of $78 \%$.RMI at cut of point of 220 has better specificity, PPV, NPV and diagnostic accuracy compared to RMI of 200.Patients with RMI value of $>=220$ has 3.66 times more likely to have malignant ovarian tumors compared to patients with RMI value $<220$.Patients with RMI value $<220$ has 0.2 times less likely to have malignant ovarian tumors compared to RMI value of $>=220$.

Table 5:Distribution of patient symptoms and signs by histopathology result in JMC,2020 


\begin{tabular}{|c|c|c|c|c|}
\hline \multirow[t]{2}{*}{ Symptoms and signs } & \multicolumn{4}{|c|}{ Histopathology result } \\
\hline & & Benign $(n=61)$ & & Malignant $(\mathrm{n}=38)$ \\
\hline Bloating & 31( & $50.8 \%)$ & 37 & $(97.4 \%)$ \\
\hline Abdominal pain & 57 & $(93.4 \%)$ & 38 & $(100.0 \%)$ \\
\hline Constipation & 12 & $(19.7 \%)$ & 32 & $(84.2 \%)$ \\
\hline Urinary compliant & 16 & $(26.2 \%)$ & 28 & (73.7\%) \\
\hline menstrual Irregularity & 26 & $(42.6 \%)$ & 18 & $(47.4 \%)$ \\
\hline Early satiety & 5 & $(8.2 \%)$ & 5 & $(13.2 \%)$ \\
\hline Appetite loss & 6 & $(9.8 \%)$ & 27 & (71.1\%) \\
\hline Family history & 1 & $(1.6 \%)$ & 1 & $(2.6 \%)$ \\
\hline Mass & 53 & $(86.9 \%)$ & 37 & $(97.4 \%)$ \\
\hline Ascites & 1 & $(1.6 \%)$ & 30 & (78.9\%) \\
\hline
\end{tabular}

According to table 5 , bloating is present in $50.8 \%$ of benign cases and $97.4 \%$ of malignant cases. Abdominal pain is present in $93.4 \%$ of benign cases and all cases of malignant tumors. Constipation present in $19.7 \%$ of benign and $84.2 \%$ of malignant cases. Urinary compliant is associated with $26.2 \%$ of benign cases and $73.7 \%$ of malignant cases. Menstrual irregularity is present in $42.6 \%$ of benign cases and $47.4 \%$ of malignant cases. Early satiety in $8.2 \%$ of benign cases and $13.2 \%$ of malignant cases. Abdominal mass is present in $86.9 \%$ of benign cases and $97.4 \%$ of malignant cases. Proportions of patients in malignant group compared to benign group is higher for symptoms and signs described in above table.

Table 6:Distribution of ovarian tumors according to histopathology in JMC,2020 


\begin{tabular}{lll} 
Benign(n=61) & Frequency & Percent \\
\hline serous cyst adenoma & 22 & 36 \\
\hline fibroma of ovary & 1 & 1.6 \\
\hline mucinous cyst adenoma & 9 & 14.8 \\
\hline dermoid cyst & 20 & 32.9 \\
\hline follicular cyst & 3 & 4.9 \\
\hline corpus luteal cyst & 2 & 3.3 \\
\hline endometrioma & 1 & 1.6 \\
\hline para ovarian cyst & 2 & 3.3 \\
Borderline serous tumor & 1 & 1.6 \\
\hline Malignant(n=38) & Frequency & Percent \\
\hline serous cyst adenocarcinoma & 24 & 63.2 \\
\hline mucinous cyst adenocarcinoma & 9 & 23.8 \\
\hline dysgerminoma & 2 & 5.3 \\
\hline clear cell carcinoma & 1 & 2.6 \\
\hline adult granulosa cell tumor & 1 & 2.6 \\
\hline Serous papillary carcinoma & 1 & 2.6 \\
\hline
\end{tabular}

Table 6 above shows that benign ovarian tumor accounts for $61.6 \%$ and malignant ovarian tumor accounts for $38.4 \%$. among benign tumors, serous cystadenoma is the most common (27.9\%), followed by dermoid cyst (32.9\%), mucinous cyst adenoma (14.8\%) and follicular cyst (6.6\%). Other benign tumors are, corpus luteal cyst (1.6\%), endometrioma (3.3\%), para ovarian cyst (1.6\%) and fibroma of ovary (1.6\%). from this study most common malignant ovarian tumor is serous cyst adenocarcinoma (60.5\%), followed by mucinous cystadenocarcinoma $(23.7 \%)$ and dysgerminoma (5.3\%). other less common types include clear cell carcinoma (2.6\%), adult granulosa cell tumor (2.6\%), serous papillary carcinoma (2.6\%) and borderline serous tumor (2.6\%).

\section{Discussion}

Among all gynecologic malignancies ovarian cancer has the worst prognosis since it is diagnosed at advance stage(10-13).Definitive diagnosis of ovarian cancer can be made only after laparotomy(13).About 10\% women undergo exploratory laparotomy for ovarian tumor during their life time(27).To detect ovarian cancer at early stage several approaches have been tried including, single cut off CA-125,USG score, Doppler USG parameters but none of them found to be effective $(11,20,22)$.Clinical 
impression and USG examinations are still major preoperative diagnostic tools for adnexal mass. However due to their limitation, Gynecologists are often faced with unexpected finding intraoperatively and has to perform unplanned procedure. RMI is the most widely used method for preoperative discrimination between benign and malignant adnexal mass $(12,13)$.

In this study the incidence of benign ovarian tumor in all patients presented with adnexal mass and operated for suspected ovarian malignancy is $61.6 \%$ and that of malignant ovarian tumor is $38.4 \%$. among malignant cases $14.3 \%$ occurs in premenopausal patients and $80.6 \%$ cases occur in postmenopausal patients and it is comparable to previous study report $(28,29)$. The mean age for benign tumor is $30 \pm 9 y$ rs and the mean age for malignant tumor is $50.6 \pm 10.8 \mathrm{yrs}$. The mean age is comparable to previous studies(30)

Most studies reported an increased diagnostic accuracy and performance of RMI with cut off $200(4,5,7,13,17,19,28)$.In this study, at cut of point $220 \mathrm{RMI}$ had high sensitivity $(84.2 \%)$,specificity (77\%),PPV(69.5\%) and NPV(88.7\%) and ROC curve showed excellent AUC 90.9\%,Cl 95\%[.843-.976].Most expert feel that screening protocol for ovarian cancer should have PPV of at least $10 \%$, that is no more than nine healthy women with false positive screening would undergo unnecessary procedure for each case of ovarian cancer detected $(3,20,31)$. Our study showed RMI at cut off point 220 had larger PPV $(69.5 \%)$ thus it could be used as screening tool. In this study, binary logistic regression analysis showed that at RMI cut of point >=220 has 17.9 times more likely to have malignant adnexal mass compared to RMI value of $<22095 \% \mathrm{Cl}[6.2-51.5]$.Systematic review of study in 2009 on 116 diagnostic studies on adnexal mass malignancy was reviewed and showed that RMI cut of 200 had sensitivity $78 \%$ and specificity $87 \%$ which is similar to our study(32). (5) at cut of point of 200 RMI had sensitivity ,specificity ,PPV,NPV of $80.5 \%, 85.9 \%, 76.3 \%, 88.7 \%$ respectively.(13) on 126 found that at cut off point of $200, \mathrm{RMI}$ had sensitivity, specificity ,PPV and NPV of 73.9\%,96.5\%,96.2\%,75.3\% respectively slightly better specificity and NPV than this study which can be explained by larger sample size in that study. ROC curve shows that when comparing CA-125 at cut off point $96(\mathrm{IU} / \mathrm{ml})$ to $\mathrm{RMI}, \mathrm{CA}-125$ has lower area under the curve (.885 vs .909) which means RMI has better sensitivity and specificity than CA-125 alone to differentiate between malignant and benign ovarian tumor. This finding is similar to previous studies $(5,7,13,15,18,23,25)$. In any scoring system to exclude malignancy ,the false negative rate should ideally be zero or close to zero(13).In our study there is five false negative cases (5/99)(5\%).two cases were dysgerminoma, one adult granulosa cell tumor, and two serous cyst adenocarcinoma.

From this study serous cystadenoma is the commonest benign ovarian tumor (36\%) followed by dermoid cyst which accounts for (32.9\%) followed by mucinous cystadenoma, accounts for (14.8\%). In this study, serous cyst adenocarcinoma is the commonest malignant ovarian cancer which accounts for $(63.2 \%)$ followed by mucinous cyst adenocarcinoma accounts for (23.8\%) followed by dysgerminoma which accounts for(5.3\%). Our finding is similar to study conducted in Addis Ababa(33). Unfortunately, serous tumors are mostly high-grade serous carcinomas and characterized by aggressive behavior, late-stage diagnosis, and low survival, contributing to the poor survival for ovarian cancer overall(27) 


\section{Conclusion}

From this study there is high proportion of women with RMl>=220 in malignant ovarian tumor group. Overall, the sensitivity, specificity, PPV, NPV and diagnostic accuracy of RMI are, $84.2 \%, 77 \%, 69.5 \%, 88.7 \%, 79.8 \%$ respectively. The study shows significant role RMI in prediction of ovarian malignancy thus helping in deciding which patients needs laparotomy and which patients need referral to a center where gynecologic oncologists are available. RMI can be used as screening tool short of reliable diagnostic method for ovarian cancer especially in developing countries.

\section{Abbreviations}

ASIR-Age standardized incidence rate

AUC-Area under the curve

BSO-Bilateral salpingo-opherectomy

BTL-Bilateral tubal ligation

CIR-Crude incidence rate

CRC-Colorectal cancer

CT-Computer tomography

HRT-Hormone replacement therapy

JMC-Jimma medical center

MRI-Magnetic resonance imaging

NPV-Negative predictive value

PPV-Positive predictive value

RMI-Risk of malignancy index

ROC-Receiver operating characteristic curve

SNNP-Southern nation nationalities and population

TAS-Trans abdominal ultrasound

TVS-Trans vaginal ultrasound

USG-Ultrasonography 
USPSTF-United states preventive service task force

\section{Declarations}

\section{Acknowledgements}

I would like to thank Postgraduate research program office who gave me the chance to conduct this study and my; deepest gratitude goes to my advisors: Dr. Fanta Asefa, and Mrs. Ayantu Kebede who gave me advice starting from proposal development to final research paper drafting. Also, I would like to acknowledge Dr. Tesfaye Urgesa (pathologist), and his colleagues who assisted me to obtain final histopathology result of study participants. Finally, I would like to thank data collectors and study participants

\section{Authors' contributions}

Both FA and AK were involved in study proposal commenting, data analysis and write up. All authors read and approved the final manuscript.

\section{Funding}

Data collection process of this study was funded by Jimma University. The funding body only followed the process to confirm whether the allocated fund was used for proposed research.

\section{Availability of data and materials}

The data sets used during current study are available from corresponding author on reasonable request at email: Bezzakedida2@gmail.com

\section{Ethics approval and consent to participate}

Ethical clearance was obtained from institutional review board (IRB) of Jimma University institute of health with reference number of IRB000218/20.Permission letter was obtained from department of Gynecology and Obstetrics and submitted to Jimma University medical center. Informed consent was taken from each study participants before data collection. All information obtained from study participants was kept with confidentiality. Participants were also told they have right to withdraw from the study at any time. All experimental protocol of this study was done in accordance with declaration of Helsinki and approved by Institutional review board (IRB) of Jimma University.

\section{Consent for Publication}

Not applicable.

\section{Competing interests}

The authors declare that there is no competing interest 


\section{Author details}

${ }^{1}$ Department of Gynecology and Obstetrics, Institute of Health, Jimma University, Jimma, Ethiopia.

${ }^{2}$ Department of Epidemiology, Faculty of public Health, Jimma University, Jimma, Ethiopia.

\section{References}

1. Richardson DL. The Role of the Obstetrician-Gynecologist in the Early Detection of Epithelial Ovarian Cancer in Women at Average Risk. Obstet Gynecol. 2017;130(3):e146-9.

2. Momenimovahed Z, Tiznobaik A, Taheri S, Salehiniya H. Ovarian cancer in the world: Epidemiology and risk factors. Int J Womens Health. 2019;11:287-99.

3. Rossing MA, Wicklund KG, Cushing-Haugen KL, Weiss NS. Predictive Value of Symptoms for Early Detection of Ovarian Cancer. JNCI J Natl Cancer Inst [Internet]. 2010 Feb 24;102(4):222-9. Available from: https://doi.org/10.1093/jnci/djp500

4. Karen J carlson. UpToDate 18. In: Barbara Goff, editor. Wolter Kluwer; 2018.

5. P. S. R, Reenu B, Prajwal S. Risk of malignancy index in ovarian tumour for predicting ovarian malignancy by using Jacob's score. Int J Reprod Contraception, Obstet Gynecol. 2017;6(4):1318.

6. Lycke M, Kristjansdottir B, Sundfeldt K. Gynecologic Oncology A multicenter clinical trial validating the performance of HE4 , CA125, risk of ovarian malignancy algorithm and risk of malignancy index. Gynecol Oncol [Internet]. 2018;151(1):159-65. Available from:

https://doi.org/10.1016/j.ygyno.2018.08.025

7. $\mathrm{FM} \mathrm{H}, \mathrm{MQ} \mathrm{A}, \mathrm{MKH}$ H. Assessment of the Value of a Modified Risk of Malignancy Index (RMI) in Preoperative Discrimination Between Benign and Malignant Ovarian Masses. Gynecol Obstet. 2017 Jan $3 ; 6(12)$.

8. Memirie ST, Habtemariam MK, Asefa M, Deressa BT, Abayneh G, Tsegaye B, et al. Estimates of cancer incidence in Ethiopia in 2015 using population-based registry data. J Glob Oncol. 2018;2018(4).

9. Bmg. Federal Ministry of Health. Fed Minist Heal [Internet]. 2015; Available from: http://bmg.bund.de/en.html

10. Jacobs IJ, Rivera H, Oram DH, Bast RCJ. Differential diagnosis of ovarian cancer with tumour markers CA 125, CA 15-3 and TAG 72.3. Br J Obstet Gynaecol. 1993 Dec;100(12):1120-4.

11. Hamper UM, Sheth S, Caskey Cl. Color Doppler Ultrasound in the Assessment of Benign and Malignant Neoplasms of the Female Pelvis BT - Radiology of the Female Pelvic Organs. In: Lang EK, editor. Berlin, Heidelberg: Springer Berlin Heidelberg; 1998. p. 69-85. Available from: https://doi.org/10.1007/978-3-642-60260-3_4 
12. Dora SK, Dandapat AB, Pande B, Hota JP. A prospective study to evaluate the risk malignancy index and its diagnostic implication in patients with suspected ovarian mass. J Ovarian Res. 2017 Aug $14 ; 10(1)$.

13. Terzic M, Dotlic J, Likic I, Brndusic N, Pilic I. Risk of malignancy index validity assessment in premenopausal and postmenopausal women with adnexal tumors. TJOG [Internet]. 2013;52(2):253-7. Available from: http://dx.doi.org/10.1016/j.tjog.2013.04.017

14. Fioretti P, Gadducci A, Ferdeghini M, Prontera C, Malagnino G, Facchini V, et al. The concomitant determination of different serum tumor markers in epithelial ovarian cancer: Relevance for monitoring the response to chemotherapy and follow-up of patients. Gynecol Oncol [Internet]. 1992;44(2):155-60. Available from: http://www.sciencedirect.com/science/article/pii/009082589290031D

15. Obeidat BR, Amarin ZO, Latimer JA, Crawford RA. Risk of malignancy index in the preoperative evaluation of pelvic masses. 2004;85:255-8.

16. Bouzari Z, Yazdani S, Kelagar ZS, Abbaszadeh N. Risk of malignancy index as an evaluation of preoperative pelvic mass. Casp J Intern Med. 2011;2(4):331-5.

17. Akdeniz N, Kuyumcuoğlu U, Kale A, Erdemoğlu M, Caca F. Risk of malignancy index for adnexal masses. Eur J Gynaecol Oncol. 2009;30(2):178-80.

18. Suchitra R, Burde K, G. N, Sahithi PLS. Evaluation of the risk of malignancy index in preoperative diagnosis of ovarian masses. Int J Reprod Contraception, Obstet Gynecol. 2018;7(10):4202.

19. Grossman DC, Curry SJ, Owens DK, Barry MJ, Davidson KW, Doubeni CA, et al. Screening for ovarian cancer US preventive services task force recommendation statement. JAMA - J Am Med Assoc. 2018;319(6):588-94.

20. Buys SS, Partridge E, Black A, Johnson CC, Lamerato L, Isaacs C, et al. Effect of screening on ovarian cancer mortality: the Prostate, Lung, Colorectal and Ovarian (PLCO) Cancer Screening Randomized Controlled Trial. JAMA. 2011 Jun;305(22):2295-303.

21. Aziz AB, Najmi N. Is Risk Malignancy Index a Useful Tool for Predicting Malignant Ovarian Masses in Developing Countries? Obstet Gynecol Int. 2015;2015:1-5.

22. Calster B Van, Timmerman D, Bourne T, Testa AC, Holsbeke C Van, Domali E, et al. Discrimination Between Benign and Malignant Adnexal Masses by Specialist Ultrasound Examination Versus Serum CA125. 2007;99(22).

23. Najmi ABA and N, Aziz AB, Najmi N. Is Risk Malignancy Index a Useful Tool for Predicting Malignant Ovarian Masses in Developing Countries? Obstet Gynecol Int. 2015;2015:1-5. 
24. Rujuta J, Nandita M. Risk of Malignancy Index ( RMI ) in Evaluation of Adnexal Mass. 2015;65(April):117-21.

25. Geomini P, Kruitwagen R, Bremer GL, Cnossen J, Mol BWJ. The accuracy of risk scores in predicting ovarian malignancy: a systematic review. Obstet Gynecol. 2009 Feb;113(2 Pt 1):384-94.

26. Bekele I, Yimam I. Cultural Sensitiveness in Health Care Delivery of Jimma University Specialized and Teaching. 2017;25:109-28.

27. RCOG, BSGE. Management of suspected ovarian masses in premenopausal women: Green-top Guideline No.62. R Coll Obstet Gynaecol [Internet]. 2011;(62):1-14. Available from: https://www.rcog.org.uk/globalassets/documents/guidelines/gtg_62.pdf

28. Timmerman D, Ameye L, Fischerova D, Epstein E, Melis GB, Guerriero S, et al. Simple ultrasound rules to distinguish between benign and malignant adnexal masses before surgery: prospective validation by IOTA group. BMJ [Internet]. 2010;341. Available from:

https://www.bmj.com/content/341/bmj.c6839

29. Sasamoto N, Babic A, Rosner BA, Fortner RT, Vitonis AF, Yamamoto H, et al. Development and validation of circulating CA125 prediction models in postmenopausal women. J Ovarian Res. 2019;12(1):1-12.

30. Rai R, Bhutia PC, Tshomo U. Clinicopathological profile of adnexal masses presenting to a tertiarycare hospital in Bhutan. South Asian J cancer [Internet]. 2019;8(3):168-72. Available from: https://pubmed.ncbi.nIm.nih.gov/31489290

31. Moore RG, MacLaughlan S, Bast RCJ. Current state of biomarker development for clinical application in epithelial ovarian cancer. Gynecol Oncol. 2010 Feb;116(2):240-5.

32. Kurman RJ, Shih I-M. The Dualistic Model of Ovarian Carcinogenesis: Revisited, Revised, and Expanded. Am J Pathol. 2016 Apr;186(4):733-47.

33. College M, Id HEH, Mondul AM, Rozek LS, Geleta T. Descriptive Epidemiology of breast and gynecological cancers among patients attending Saint Paul 's Hospital Millennium. 2020;1-11. Available from: http://dx.doi.org/10.1371/journal.pone.0230625

\section{Figures}




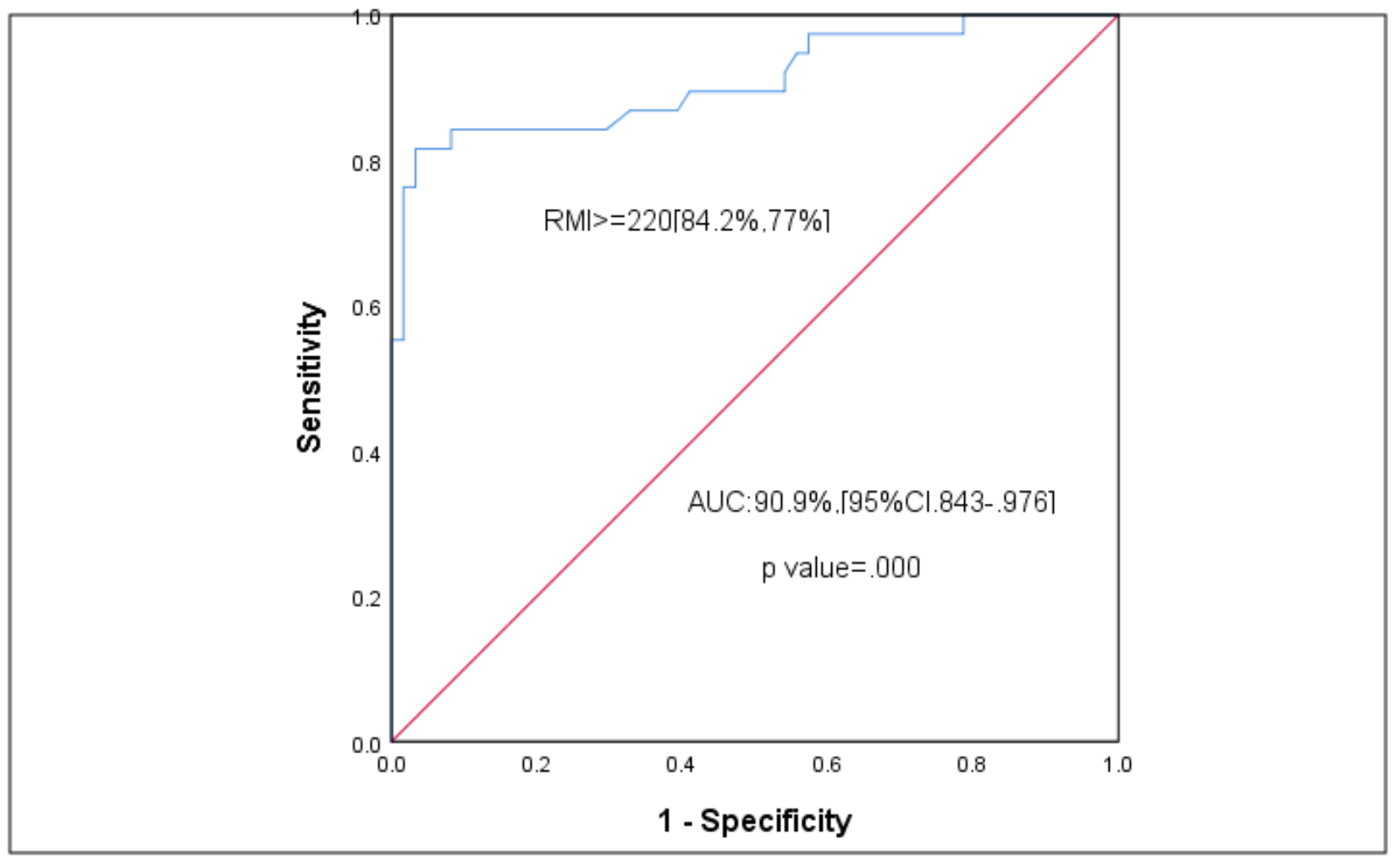

Figure 1

ROC curve of RMI for discriminating between benign and malignant adnexal mass in JMC,2020 


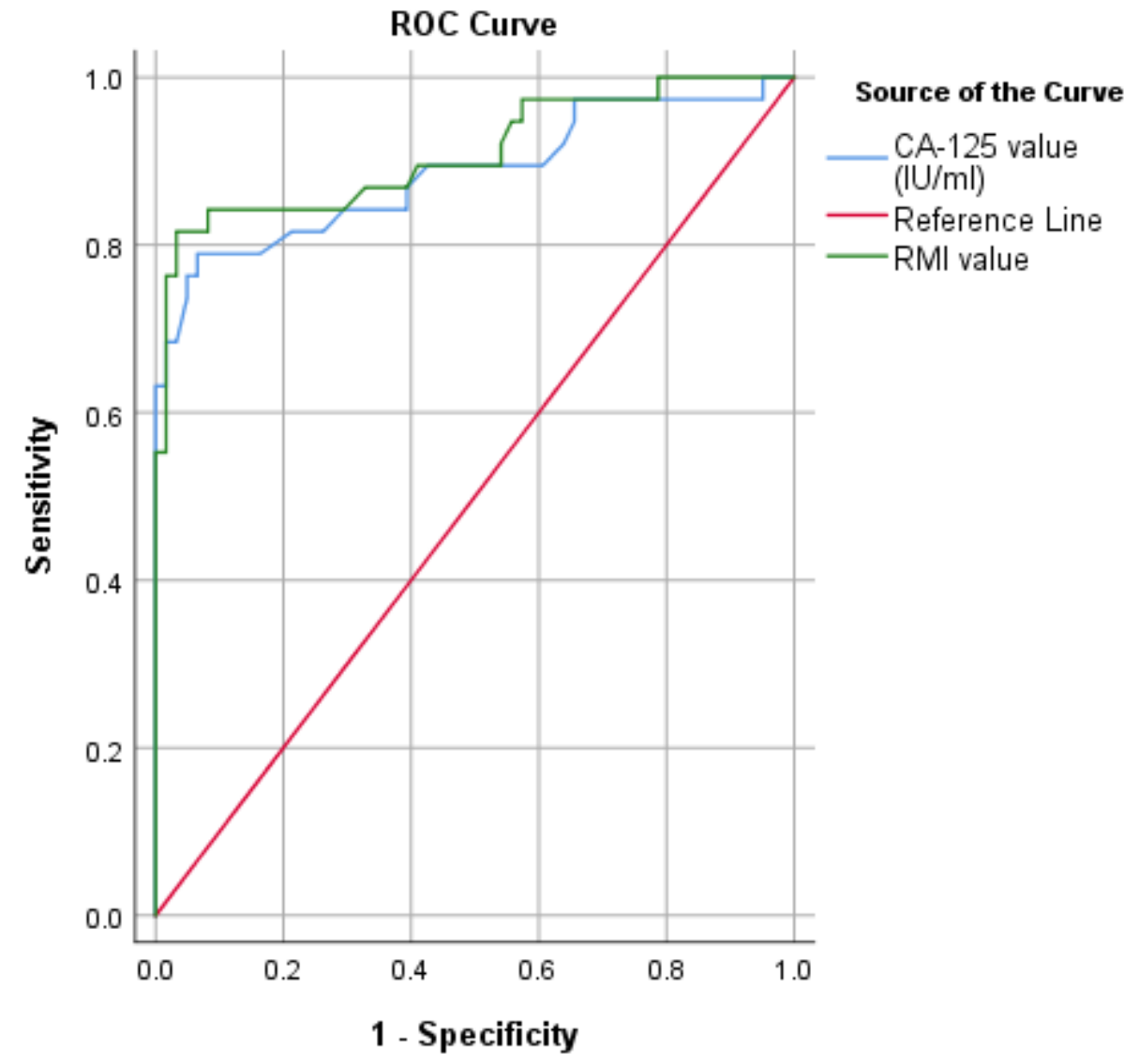

Figure 2

Comparison of ROC curves of RMI and CA-125 for discriminating between benign and malignant adnexal mass in JMC,2020 